\title{
Public Support for Policies: Public Opinion and Policy Making
}

Eva Kyselá, Katedra sociologie, Filozofická fakulta, Univerzita Karlova

A B S T R A C T

Increasing policy feasibility is a frequent argument for policy relevance of research on public attitudes to policies. Therefore, this text discusses the interlinkage of public opinion and the policy-making process. The text focuses on the role of public opinion surveys as a source of information about public attitudes towards policies and policy instruments. Following a discussion of conditions of policy responsiveness related to poll measures of public support, public support is argued to emerge from public opinion as a communication process or a process of social organization, rather than to reflect a collective state of mind. As such, public support constitutes one of many possible results of the public opinion communication process - a result which is temporary and thenceforth subject to the ongoing process. It is not reducible to survey responses as expressions of individual attitudes toward policies, which present an oversimplified and partial picture of reality. Surveys, however, constitute an important source of information for researchers and policy makers. Therefore, we need to use and interpret them accordingly. Some recommendations are proposed to improve the current practice.
K E Y WOR D S :

public opinion

policy attitudes

public support

policy responsiveness

policy representation

D O I L I N K :

http://doi.org/10.13060/121443 $8 \times .2018 .2 .16 .451$ 


\section{Introduction}

Regarding public opinion as an important factor of policy feasibility, policy makers and researchers have been increasingly interested in public attitudes to policies. While many authors argue that public attitudes toward policies and policy proposals are of great importance to the process of policy making, only few have spent some time explaining why and in what way this is the case [e.g., Bernauer, Gampfer 2015]. In general, public opinion research in political science lacks wider theoretical and conceptual debate [Burstein 2006; Druckman 2014]. Public policy theories rarely consider public opinion explicitly [Beyer, Hänni 2018] and political sociology omits public opinion almost entirely from its considerations [Manza, Brooks 2012]. At the same time, however, research of public policy support or acceptability of policies is proliferating, as well as studies into policy responsiveness to and congruence with public opinion. Despite the growing body of research, our knowledge about interaction between public opinion and policy making, and the actual importance of policy support studies, is still limited [Wlezien 2016]. Such knowledge, however, can improve research practice and inform measurement of policy attitudes by pointing out the limits of the measures used and the opportunities for advancement of new methods or approaches, and by reflecting their uses and roles in the policy-making process. The scope of the research on public attitudes toward policies is currently quite narrow [see, for example, in the field of climate change] and can be significantly broadened and enhanced by a critical discussion of the interaction between public opinion, its measurement, and its effects and uses in policy making.

Given its embeddedness in complex social systems, public opinion is a concept hard to define. A debate on the status of surveys and polls as representations of public opinion, or its parts at least, is still going on, while surveys are undoubtedly firmly incorporated into the social institutions of modern societies. As such, public opinion is often reified or objectified as survey results, losing its complex nature in this simplified portrayal of popular will. Similarly, public support is most often a matter of shares of the public which positively evaluate a policy in a survey (marginals), usually imbedded in ideas of acceptability, acceptance, support, or opposition [Kyselá 2018], thus ignoring other possible responses, as well as different dimensions and context of the policy itself. Measures generally rely on statements about how acceptable respondents find a policy or how supportive of the policy they are.

Public support, however, emerges from public opinion as a communication process [Crespi 2013] or a process of social organization [Price, Roberts 1987], rather than reflecting a collective state of mind. As such, it involves a specific social organization of actors, both collective and individual, and constitutes one of many possible results of the public opinion communication process - a result which is temporary and thenceforth subject to the ongoing process. It is not reducible to survey responses as expressions of individual attitudes toward policies [Eagly, Chaiken 1993].

Distinguishing between public support as a specific social organization in which approval of policies or policy instruments prevails and creates a pressure or demand for such a policy, on 
one hand, and survey results (currently dubbed public support), on the other hand, is of crucial importance for interpreting results and asking research questions. Claims about general public support for policies based on survey results are oversimplified and hence possibly misleading or just of inadequate information value. At the same time, surveys are an important, hard-to-replace tool. A reconceptualization of public attitudes and responses toward policies is therefore needed in order to improve the current practice and increase the value and possible impact of studies on policy attitudes.

The text is organized as follows: issues with using a simplified concept of public support as survey results are pointed out in a discussion of conditions of policy responsiveness. The focus is on the interlinkage between policy making and perceived or mediated "public opinion", i.e. polls and surveys as mediated representations of public attitudes and responses to policies. Proposing some conclusions on the nature of the relationship between public opinion and policy making, arguments to remedy the relevance of surveys on policy attitudes are made based on a more complex take on public opinion as a process of communication and social organization interacting reciprocally with the process of policy making. A distinction between public support as a possible and temporary result of the public opinion process and policy responses as measured in surveys is argued and implications for measurement practice are discussed.

\section{Responsiveness to public opinion and policy support}

The importance of attitudes of the public toward policies in the policy-making process is commonly stated in empirical studies [e.g., Gaunt, Rye, Allen 2007; Kallbekken, Sælen 2011; Kraft 2011]. Decision makers would apparently not risk passing laws not supported by citizens or accepted by consumers in the marketplace [Druckman 2013]. The assumptions that public opinion matters in policy making and that surveys and polls, as its representations, are considered by policy makers in their decision making are generally derived from the focus of representative democracies on elections - a key characteristic of modern democracies is their governments' responsiveness to "preferences" of citizens [Dahl 1971: 1] ${ }^{1}$. As representatives are elected by the public, they have an inherent motivation to pay attention to the public's wishes and evaluations of governmental actions [Erikson 2007]. Brooks and Manza [2006: 500] argue that the "assumption is that the structure of democratic political institutions gives government officials incentives to incorporate information (or make heuristic attributions) concerning the preferences of the electorate". Among others, this assumption is probably the reason why most researchers do not argue for the importance of policy attitudes and their measurement.

Such assumptions are usually founded in a specific model of the policy-making process [Price, Neijens 1997; Althaus 2006] in which the public acts in different stages and diverse roles. According to a general model, the policy-making process has five broad stages which occur

Bartels [2003] argues that citizens do not have preferences, but attitudes, since the key axioms of preferences are rebutted by an abundance of empirical research. 
more-or-less in this order: (1) elicitation of basic values and problem identification, (2) development of options and possible solutions, i.e., policies, (3) estimation of their consequences, (4) evaluation of selected alternatives, and (5) the final decision [Price, Neijens 1997]. All actors enter this process in every phase and theories differ as to who has the largest influence when. Public opinion can be used or influential basically in all stages by "identifying issues requiring political action", "applying or resisting political pressure", "holding politicians accountable to the public's preferences", and "formulating policy" [Althaus 2003: 257].

A majority of public opinion researchers assume public opinion to enter the process at the semi-final stage of evaluation of alternatives [see also Price, Neijens 1997; Althaus 2003], although other authors have pointed out the influence of public opinion in the first stage of the policy-making process. Easton [1965; see Roberts 2011 for a short summary] states that policy making is responsive to three types of inputs: demands (problems are identified by groups which than pressure policy makers to address them), resources (financial, human, information, and other), and supports: democracy is viable only as long as the governed support it at least passively (obey laws, pay taxes, accept election results etc.). Public opinion can influence policies in terms of both demands and support. Its forms and effects are, however, likely different in these two roles.

The empirical evidence in support of these assumptions and models seems to be quite broad, but not yet fairly conclusive [Page 1994; Burstein 2003, 2010; Olmastroni 2010; Shapiro 2011; Wlezien 2016; Beyer, Hänni 2018]. A highly-cited early work by Page and Shapiro [1983] can be regarded as a tipping point in the ascent of policy and democratic responsiveness studies in a variety of fields, including the broad area of welfare policies [e.g., Mehrtens 2004; Christian 2008; Manza, Brooks 2012] or governmental action in general, different policy domains in particular [Stimson, MacKuen, Erikson 1994; Soroka, Wlezien 2010b; Hakhverdian 2012; Vandeweerdt, Kerremans, Cohn 2016], as well as (scarcely so far) in environmental policy [Johnson 2005; Agnone 2007; Weaver 2008].

Despite the wealth of literature, Burstein's [2003] summary of existing research concluded that the field had developed in volume, but not in theoretical background: "it may be argued that the range of predictions about impact [of public opinion] based on democratic theory has widened in the past 20 years, not narrowed, and that researchers are not closer to consensus now than they were then" [Burstein 2003: 30]. Although another fifteen years have passed since Burstein's evaluation, not much has changed [Wlezien 2016; Beyer, Hänni 2018]. Apparently, public opinion has some impact sometimes [Manza, Cook 2002; Burstein 2010], which is not by itself a very convincing conclusion. Burstein [2003], on one hand, concludes that represented public opinion has a significant impact on policy in three-quarters of the studies he reviewed. On the other hand, Gilens and Page [2014] make a compelling empirical case for dismissing the majoritarian theory of democracy in the US in favour of economic-elite domination and biased pluralism. Krosnick and MacInnis [2013] support this conclusion with results of public opinion polls consistently showing positive evaluations of governmental action on climate change. Yet this general public consensus remains largely ignored by the U.S. administration [also Brewer 2004]. 
In consequence, policy responsiveness or congruence seems to occur depending on situation, forms of social organization, and conditions. Vanderweerdt and colleagues [2016], for example, argue that policy representation can only occur if:

- the issue is salient and important enough,

- the public sufficiently understands the issue and has stable attitudes about it,

- there is a clear majority preference for action or one option in the overall opinion.

The following paper discusses these points with respect to the concept of public policy support as public opinion expressed about proposed policies and policy instruments. In these conditions, it becomes quite clear that such measurement of public support is inadequate, given the potential for policy responsiveness, and can be easily misunderstood, objectified or reified.

\section{Issue saliency and policy}

First of all, the issue to be handled by a policy needs to be presented for or perceived by the people as salient and important enough to even care or pay sufficient attention to form an opinion, to have an attitude, and eventually to exert some pressure on policy makers. Citizens are more likely to give reasoned opinions on more salient issues and issues they are more interested in [Ciuk, Yost 2016]. According to empirical evidence, saliency plays a significant role in policy responsiveness to public opinion [Burstein 2003], since citizens may leave the decision on non-salient issues to other actors. This, however, does not necessarily mean that the public loses against interest groups [Burstein 2006]. Moreover, public opinion has been shown to have effect both independently on other actors (or on collective behaviour) and through them [Burstein, Linton 2002; Weaver 2008; Vandeweerdt, Kerremans, Cohn 2016]. There is also some evidence for an amplification mechanism between public opinion and protest behaviour of environmental movements which increased issue saliency [Agnone 2007].

Saliency, therefore, needs to be understood simultaneously as an outcome and an input of the public opinion process. It is not an inherent quality of the debated issue. Rather, it is constructed within social processes and communication. As a variable, it tends to be treated as a given characteristic that influences opinion, while in fact it is a part of that opinion continually negotiated in interaction with other aspects of public opinion and public debate. In consequence, we know little about the ways issues or policies become salient.

Most of the research on policy responsiveness has been done on highly salient issues [Page 2002]. Assessing surveyed public support for policies related to issues of low salience is problematic for several reasons. First, citizens are likely to construct attitudes ad hoc or based on cues, policy characteristics, and other variables, which are usually not monitored in the survey [Rugeley, Gerlach 2012; Bernauer, Gampfer 2015]. Second, as support can involve more active engagement, other responses would be more suitable in cases the issue is not salient - the policy can be, for example, tolerated, or the respondent does not even care what policy would be implemented (if any). Third, saliency may change and with it, respondents not interested in the 
policy may quickly become more engaged and change their passive attitude. With high-salience issues, demands can emerge in public opinion, i.e., active pressuring on policy makers to take (a specific) action. Measuring support, acceptance or acceptability, however, adheres to the role of public opinion as support, rather than demand. Demands and pressures posed by the public may therefore remain only hinted on or be misinterpreted in surveys.

Furthermore, not all citizens have to hold opinions on all issues. Interest in policy issues is probably differentiated across the public - while some groups will not be interested at all, others will form an issue public concerned about the particular issue and even exerting pressure on policy makers [Nisbet 2011]. Sartori [1993] argues that having a partially uninterested public is a good thing - with formulation of opinions, citizens are inclined to extremes. Without a group of indifferent voters in the middle, extreme political parties would regularly win more support and pose a threat to democracy. Therefore, it may be enough to have some non-trivial number of respondents holding and expressing opinions [Soroka, Wlezien 2010b].

The fact that saliency arises in the communication process, with media, the public, and policy makers reinforcing or weakening it by continuing or muting the public debate, has important implications for the public attention, the amount of information about the issue or policy in the public sphere, and hence also for the knowledge of the public.

\section{Informed public}

A problem debated with regard to asking people about their attitudes toward policies is whether they understand the proposed policy. To be responsive, to voice meaningful opinions, and to hold the government accountable for its actions, citizens need to be attentive of those actions and decisions, and knowledgeable about their context and consequences, at least for themselves. Hence, the usual argument is that the more information the public has, the better for democracy. Ill-informed citizens, on the other hand, cause concerns about whether the public is competent enough to contribute in any meaningful way (other than by voting) to policy decision making and whether it can have any (sound) opinions at all. ${ }^{2}$

Citizens are likely not well informed about all of the policy issues concerning them and policy options suitable for handling those issues. People are willing to give opinions on policies they neither know nor understand as well as on non-existent or highly obscure issues [Moy 2008]. Public opinion on policies has been accused of being fickle and dependent on measurement and

2 The centrality of knowledge and information in this debate originates in the rationalism of the Enlightenment period - not being knowledgeable equals not being free [Ramonet 2003]. Consequently, the increase in communication and the coming of the information era have been regarded mostly as positive in this respect. There is, however, also a reverse side to this - the unprecedented growth of information not only provided to people, but literally loaded onto people in a constant information overload, has also been identified as a threat to democracy [Sartori 1993]. Sartori [1993] even suggests that political apathy of citizens is not a consequence of too little information or education, but rather of too much of it. The endless information flow numbs people, making their attention highly selective. 
framing; some argue that the seemingly contradictory attitudes are indicative of misinformation or lack of information [Converse 2006].

Different remedies to the problem of citizens providing answers to survey questions they do not know much about have been proposed in the literature, including attempts to provide respondents (and citizens) with more information, arguing that citizens are able to reach meaningful opinions with the use of shortcuts and heuristics [e.g., Rugeley, Gerlach 2012], using the "Don't know" or "No opinion" response options [Althaus 2003], attention checks [Huang et al. 2012; Meade, Craig 2012], question filters, measures of opinion intensity etc. [Price, Neijens 1997 for a short overview; see Althaus 2003], and aggregation of attitudes [Erikson 2007; Page, Shapiro 2010]. No such methodological remedy, however, refutes the main points of criticism with respect to the inability of ill-informed citizens to provide meaningful and stable opinions or hold the government accountable.

Yet the public can also be accepted as it is - ill-informed for the greater part. One can regard this state the way, Althaus [2006: 91] suggests, it was regarded for most history - as a "given", rather than a "crisis". "Classical" democratic theory formulates no universal expectation of citizens to be informed on every issue (or even most issues) discussed in the public domain [Althaus 2006]. As a matter of fact, policy making is the only domain where citizens are expected to be experts or at least to be universally knowledgeable [Soroka, Wlezien 2010b]. In any other field outside their own job, they are discouraged from making their own conclusions [Ramonet 2003]. Moreover, Staerklé [2009: 1096] argues that "most citizens are actually aware of political alternatives, but not necessarily in their expert formulations. They know the kind of society they are attracted to and the models of society they oppose, in terms of its level of cultural diversity, individual freedom or social equality, for example. [...] Accordingly, policy attitudes refer to individual evaluations concerning the desirability and legitimacy of different models of society."

The inconsistency of attitudes may, therefore, not be a consequence of being ill-informed, but also of the ambivalence and inconsistencies inherently present in political culture and of competing values or models of social organisation [Staerklé 2009; see also Hochschild 1981]. In order to be fair to citizens when assessing their knowledge and understanding of issues and policies, researchers should be aware that implicitly, they often ask whether the respondents understand the policy in the way experts do. In consequence, one should rather ask how the respondents understand it, thus acknowledging the plurality of rationalities people may apply, especially on policy issues surrounded by uncertainty and ambiguity, such as climate change and other systemic risks [Rosa, McCright, Renn 2013]. Different rationalities are likely distributed between the public and the issue public, as discussed above, and may lead to different strategies, preferred policy solutions, and responses to proposed policies. Once again, therefore, policy support surveys seem inadequate for and oversimplifying of not only the overall public process of communication, but individual attitudes as well. 


\section{A clear majority preference}

Having only a part of the population sufficiently informed and opinionated, it is clear that looking for a clear majority preference in society is difficult. There is no clear cutoff level of overall popular acceptability or support, i.e., a share of citizens in favour or opposition of a policy that is high enough to safely conclude that a policy is acceptable or supported and should be implemented. In short, there is no "popularity threshold" [Pawson, Wong 2013: 446]. In consequence, Vanderweerdt and colleagues [2016] condition of policy responsiveness is hardly attainable. This is especially true with respect to general measures of support or acceptability, or measures using hypothetical policies, since they might not translate into support for specific policies that easily [Krosnick, MacInnis 2013; so called 'principle-implementation gap'; see Dixon, Durrheim, Thomae 2017].

Furthermore, given the context dependency of policy responses, there is no single universal type of public response that could be safely interpreted as universal support. In consequence, the informational value of results describing shares of population that declared support for or acceptance of a policy is limited, especially in the policy-making process. Rather, researchers can explore readiness to respond in different ways, e.g., by attitude construction, affect, or behaviours, to policy proposals in order to inform the process of policy formulation and implementation and to propose when and under what conditions a policy is more likely to be positively evaluated [Pawson, Wong 2013]. That way, researchers and policy makers would be better equipped to assess the contingency and conditions of positive evaluation of policies.

\section{Public support and the public opinion process}

Following the discussion of the three main conditions of policy responsiveness, it becomes clear that the concept of public support, as it is currently used and measured, is oversimplified and hinders the measurement of actual public attitudes and policy responsiveness to those attitudes. There are three key points based on the conditions of policy responsiveness to surveys measuring policy attitudes:

- issue and policy saliency are evolving in public debate and influence a diversity of public responses to policies as well as policy responsiveness to public attitudes. Different public responses may be expected consequent on different levels of saliency and attention paid by the population;

- the public may not be knowledgeable of policy issues and solutions, but it has general ideas about a wanted kind of society, which may not adhere to expert formulations used in policy making. Thus, people's understanding of policies may differ, invoking different responses or attitudes;

- there is no popularity threshold or criterion for determining, based on survey results, when a policy is generally supported or accepted by the public. 
In consequence, public support as measured in surveys and polls is an oversimplification, reflecting reality only partially, which makes it harder for policy makers to respond to public opinion.

Public support, like public opinion, is often reified through surveys, and their results and treated as an object, a relatively stable characteristic of the population (a distribution of opinions), or even a single public decision. Nevertheless, "[p] ublic opinion is neither a group, institution, or structural aspect of a society nor the discrete states of mind of a set of individuals. Rather, it refers to continuous interactions and outcomes" [Crespi 2013: 2; emphasis by EK]. As such, public opinion forms around issues and evolves in time [Price, Roberts 1987].

Similar to public opinion polls, studies of public attitudes and responses to policies represent only a fraction of the complex communicative nature of public opinion as a social and communication process involving other actors such as groups and organisations [Price, Roberts 1987] or as a continual interactive and communicative system of plurality of actors and levels of communication [Crespi 2013]. Surveys of attitudes are part of the process as mediated representations of public responses to an issue [Price, Roberts 1987]. Together with other such representations, such as the media's take on the public and the public debate, activism, and others, survey results lay ground to perceived "public opinion". Public opinion as such, however, is by no means reducible to the former. Unfortunately, the distinction between perceived "public opinion" and public opinion in the broader sense, as a communication process and social organization, is rarely made by authors who argue that public support is important to policy makers. This is indeed an important distinction to make when studying policy attitudes and talking about public support.

Public support is not the public's "state of mind" that could be accurately measured by surveys. Rather, it is the public's issue-specific "state of social organisation" [Price, Roberts 1987: 804]. Part of this social organisation is the policy-making process itself. Hoff-Elimari and colleagues [2014] argue that the relationship between public opinion and policy making should be thought of as a system of feedback loops, "comprising both a dynamic policy representation and a dynamic public responsiveness". The responsiveness of the public, in their perspective, however, is not limited to adjusting the order of policy preferences or giving positive or negative electoral incentives, but also involves normative responses and changes in values, behaviours, and beliefs [Soss, Schram 2007; Campbell 2012; Pacheco 2013]. Citizens may even adapt their values to values implicitly (or explicitly) present in policies, institutions, and overall governmental discourse [Svallfors 2010; Hoff-Elimari et al. 2014].

Policy feedback is not only organizational and economical, but also normative [Svallfors 2007]. Such responsiveness on the part of the public is not warranted and may especially apply to policies that are visible and proximate to citizens' everyday lives [Soss, Schram 2007]. By acknowledging and using these mechanisms, positive attitudes toward certain policies can be gradually built at each step of the policy process [Pacheco 2013]. Cox [2010] argues that policy legitimacy is best gained by linking policy with certain values, preferably those which will resonate among the public. Similarly, Matti [2009: iii] defines policy legitimacy as "the extent to which values and beliefs underpinning public policy content correspond to those established among the public”. In consequence, public support can be built by gradually aligning values 
embodied in the policy with those of the public. It emerges through exchange and mutual interpretation of meanings between the public and policy making.

Contingency of policy attitudes and public preferences on political messages [Druckman 2014] is, to a degree, inevitable and inherent to the communication processes between policy and public opinion. Strictly speaking, an effort to increase policy acceptability by policy formulation is a form of influencing, even manipulating, public opinion, while it is an often-provided reason for conducting studies of policy attitudes. These studies, by their own right, constitute a feedback loop between public opinion and policy formulation (i.e., they form a part of the perceived "public opinion"). Therefore, there is no point in holding simplistic views of unidirectional causality or to dismiss influence of public opinion on policy on the grounds of elite manipulation.

In consequence, it may be pointless to try to identify causal mechanisms of policy responsiveness. Rather, researchers should focus on interactions of different actors and communication processes through which both public opinion and public decisions emerge. Examining social organisation around issues can furthermore shed some light on when and how the public opinion process gains political relevance, identifying with a more holistic and contextualised perspective what actors play key roles in issue-specific organisation and communication processes, what communication strategies are used and how, what is the distribution of power and access to communication channels, etc.

Taking this processual approach to public opinion, public support is defined here as a temporary result of the public opinion process, say a "momentum", furthermore subjected to it and therefore susceptible to change. It involves survey results as mediated public opinion, along with other actors and mediations, and encompasses the overall public debate, however hard to measure or quantify. Public support is a result of public opinion as a set of interlinked processes which are public "in the sense that they operate together, across levels, in shaping collective responses to social issues" [Price, Roberts 1987: 781]. For easier distinction from its previous use, the concept of public support as presented here could also be termed popular support.

Importantly, public or popular support is only one of many possible temporary results of the public opinion process, alongside opposition, apathy, tolerance and other possible responses to policies. It is also by no means reducible to any single policy response measured in surveys, whether termed support or acceptance, opposition, favour, or disfavour. These are only a few out of many possible evaluative expressions of policy attitudes [Eagly, Chaiken 1993] as measured in surveys.

There are generally two kinds of current measurement of so-called policy support, acceptability, or acceptance [Kyselá 2018]. First, there are general measures answering the information needs of the first stage of the policy-making process as discussed at the beginning of this text, i.e., identification of problems and salient policy issues. These measures are usually concerned with general governmental action and do not specify the type of policy, its costs, or other characteristics. Second, there are measures evaluating a specified policy or policy instruments. They 
attempt to answer questions such as "Will this policy be accepted?", which correspond to the evaluative stage of the policy-making process.

By focusing on policy acceptability, support, and acceptance, however, researchers reproduce the prevalent top-down policy perspective [Batel, Devine-Wright, Tangeland 2013] in which the public is presented with a policy proposal to evaluate, without otherwise participating in its formulation. Such a research focus corresponds only with one phase of the policy-making process and a limited number of research questions. It also concerns mostly public support as input to the policy-making process, while overlooking demands. Other research questions can be asked and other evaluative responses, as expressions of attitudes, can also be studied [Devine-Wright et al. 2017]. Respondents should also be given space to formulate their views in a more proactive way, rather than responding to issues selected by researchers or policy makers [Althaus 2003; Tvinnereim et al. 2017].

Public responses to policies in surveys, such as support, can be misleading with respect to the public's preferences and attitudes, since some citizens may be opposed to a proposed policy because they do not want any such policy and others because they want a far stricter policy. Therefore, we cannot say how much policy citizens want based on their expressed levels of positive (or negative) evaluation. Such evaluation may even be unanchored to the policy status quo [Wlezien 2016]. Alternative approaches such as the thermostatic model of policy responsiveness [Soroka, Wlezien 2010a, 2010b] attempt to remedy this problem. The model is focused on relative preferences, which represent the difference between actual spending in different policy domains and the public's preferred level of spending [Johnson, Brace, Arceneaux 2005; Soroka, Wlezien 2010a, 2010b; for application of the model, see, e.g., Bendz 2015]. The use of relative preferences assumes a reciprocal relationship between policy and public opinion - if public opinion changes, policy follows in response. If spending increases or decreases, relative preferences change accordingly to match the current situation. Such a model better corresponds with the nature of public support as a temporary result of public opinion process.

\section{Conclusion}

This text has argued that public support (and, similarly, public acceptability or acceptance) as used in most of the existing research on public policy attitudes, is an oversimplified concept, one that limits the scope of research and biases what we know about public attitudes toward policies, since it is not only a fraction of overall public debate, but also a fraction of possible policy responses and preferences among the public.

A distinction between public (or popular) support and measured public policy responses was made, defining public support as one possible temporary result of the public opinion process which includes, but is by no means reducible to, public opinion surveys measuring public responses as expressions of attitudes toward policies. Public opinion surveys are, therefore, only a partial and momentary reflection of public opinion and attitudes toward policies - reflection 
which is often reified as a characteristic of the public or its single decision, as a state of public support, acceptance, or opposition. Such reification and objectification are likely natural parts of policy making as a communicative process involving negotiation, competing discourses, persuasion, and often populism. In this respect, surveys and their results are used as an instrument in these processes, often to accomplish something, to gain power, or to claim legitimacy.

Representations of public opinion, referred to here as perceived public opinion, are simultaneously co-constructed and represented by research measurements and instruments [Perrin, McFarland 2011] and thus form a part of the entanglement between public opinion and policy-making processes. "A question asked by an interviewer changes an abstract and perhaps irrelevant matter into a genuine subject of action; [...]. The conventional poll forces expression into predetermined channels, by presenting clear-cut and mutually exclusive choices. To accommodate one's thoughts to these channels represents for the respondent an arousal of interest, an affirmative act" [Bogart 1967: 335]. Hence, researchers should ask difficult and maybe uncomfortable questions about their work and research practices. Part of this task is to examine carefully the measures we use in our research.

Following this argumentation, a change in prevalent measures of public policy attitudes and a reconceptualisation of the ways we interpret results of existing policy acceptability or policy support studies are needed. First, if researchers are to examine public opinion in order to elicit values and identify policy problems needing attention, respondents should be given space to formulate their views in more proactive way rather than responding to issues selected by researchers or policy makers [Althaus 2003; Tvinnereim et al. 2017]. This requirement certainly calls for new techniques and data collection methods, including the use of mixed designs [Page 1994].

Second, if we want to explore policy attitudes and their implications for policy making, or possible reactions and responses of citizens to proposed and implemented policies, we should do so in terms of readiness or potential for acceptance/support, rather than actual acceptance/ support. The word acceptability - the ability to accept - in fact hints to this potential. Instead of claiming that there is overall support for policies, researchers should claim that there is high potential for policy support. Such interpretation weakens our conclusions but, more importantly, it weakens the assumptions we rely on in making claims about the public. The best evidence studies can offer to policy makers is a proposition of when a policy is more likely to be supported and what elements need to be in place [Pawson, Wong 2013].

Hence, instead of assuming citizens to be always opinionated on all policies, we should explore what potential they have to form a positive opinion on a policy once it is proposed and the public is provided with more information about it. The slight shift in perspective would allow us to bridge the arguments that people can have policy-specific preferences, on one hand, and that they rather have preferences about the degree or contours of governmental activity in general, on the other hand [Stimson, MacKuen, Erikson 1994; Wlezien 2004]. Citizens are more-or-less likely to develop policy-specific opinions (or context-dependent preferences) based on a diversity of attitudes, values and worldviews, including attitudes toward policy instruments, parties 
proposing the policy, and the policy issue [Zvěřinová, Ščasný, Kyselá 2014; for a review in the climate policy domain, see Kyselá 2018]. The idea of being ready to form an opinion, rather than having formed one, could also help us better grasp the framing effects and all the considerable changes in respondents' answers that cast doubt on the existence of public opinion as such. Moreover, most policies presented to respondents in surveys are hypothetical. Therefore, in their decision-making, respondents lack the context of public debate and certain social organisation around the policy issue at hand, and their opinion may change depending on context, conditions, and forms of social organisation.

Moreover, rather than just monitoring how acceptable a policy might be, different beliefs, understandings, and practices related to a policy and the behaviour affected by it could be explored as part of public opinion, including perceived barriers and policy characteristics such as effectiveness or fairness of distribution. Such insights could help in devising communication strategies, building trust, and adjusting policy-making processes, which would, in consequence, contribute to a more positive evaluation of proposed or implemented policies [for the example of procedural justice, see Tyler 2000].

Policy makers are interpreters of survey results as well. Their interpretations and uses of them should also be studied, as they constitute an important part of policy representation and responsiveness. The ways in which public opinion is reified in communication processes can be very informative about discourses and mediation of public opinion in the policy-making process. Recently, researchers began to examine public reactions to and interest in policy responsiveness [Esaiasson, Wlezien 2017] and their effect on public attitudes to policies [Esaiasson, Gilljam, Persson 2017]. Such endeavour includes public perception of not only the policy-making process but also of the ways it is reflected or mediated in the process, either by public opinion survey results or other media (in the broad sense of the term). Furthermore, it stresses the importance of studying the processes of communication and reification of public opinion and its use in negotiation of policies, but also meanings.

Third, the conditions and social organisation in which representation occurs or does not occur should be studied, including issue saliency, citizens' knowledge, stability and context dependency of policy responses and attitudes, the role of different actors, and the nature of interactions within the public opinion process. Namely, with respect to issue saliency, one should examine its nature, negotiation, and social construction as a process, not only as a given characteristic of an issue - what issues become salient and how, in what communication and interaction process, within what discourses, and in response to what interests, other issues, or overall social and economic situation?

Although empirical studies on citizens' knowledge are plenty and we have a great deal of interesting and important findings at our disposal, there is still much more to explore. For example, as discussed, knowledge regarding specific issues varies greatly within population, with interest often being its correlate. Therefore, we need to study issue publics, i.e. citizens interested in, knowledgeable about and often engaging with an issue, examining how knowledge is distributed 
in society, how different rationalities are constructed, whether and how this is related to power distribution, or what role issue publics play in the opinion and policy-making processes.

Last but not least, the specific social organisation around a policy issue, including actors and their interactions, is crucial in the study of conditions of policy responsiveness. For example, Devine-Wright and colleagues [2017] argue that studying public acceptance means examining different scales of communication in terms of content and process, i.e. how meaning is constructed and power distributed in interaction of groups, in order to understand how a technology (or policy) is understood and presented by different actors and groups. Public opinion and policy-making processes are interactive and reflexive in their nature [Disch 2011; Esaiasson, Wlezien 2017], since different actors reflect them, their parts, their outcomes, and meanings constructed within them, but the same actors take part in these processes as well, continually changing them based on their reflections and understandings. In consequence, studying these processes is a great challenge requiring new approaches to be taken and new questions to be asked.

L I T E R A T U R E

Agnone, Jon. 2007. „Amplifying Public Opinion: The Policy Impact of the U.S. Environmental Movement." Social Forces 85 (4): 1593-1620, https://doi.org/10.1353/sof.2007.0059.

Althaus, Scott L. 2003. Collective Preferences in Democratic Politics: Opinion Surveys and the Will of the People. Cambridge, UK : New York: Cambridge University Press.

Althaus, Scott L. 2006. „False starts, dead ends, and new opportunities in public opinion research." Critical Review 18 (1-3): 75-104, https://doi.org/10.1080/08913810608443651.

Batel, Susana, Patrick Devine-Wright, Torvald Tangeland. 2013. „Social acceptance of low carbon energy and associated infrastructures: A critical discussion.“ Energy Policy 58 : 1-5, https://doi.org/10.1016/j.enpol.2013.03.018.

Bartels, Larry M. 2003. „Democracy with Attitudes. “ Pp. 48-82 in MacKuen M. B., G. Rabinowitz (eds.). Electoral Democracy. Ann Arbor: The University of Michigan Press. Bendz, Anna. 2015. „Paying Attention to Politics: Public Responsiveness and Welfare Policy Change.“ Policy Studies Journal 43 (3): 309-332, https://doi.org/10.1111/psj.12098.

Bernauer, Thomas, Robert Gampfer. 2015. „How robust is public support for unilateral climate policy?“ Environmental Science \& Policy 54 : 316-330, https://doi.org/10.1016/j.envsci.2015.07.010.

Beyer, Daniela, Miriam Hänni. 2018. „Two Sides of the Same Coin? Congruence and Responsiveness as Representative Democracy's Currencies." Policy Studies Journal 46 (S1): S13-S47, https://doi.org/10.1111/psj.12251.

Bogart, Leo. 1967. „No Opinion, Don’t Know, and Maybe No Answer.“ Public Opinion Quarterly 31 (3): 331-345, https://doi.org/10.1086/267533. 
Brewer, Thomas L. 2004. „US public opinion on climate change issues: implications for consensus-building and policymaking.“ Climate Policy 4 (4): 359-376, https://doi.org/10.1080/14693062.2004.9685531.

Brooks, Clem, Jeff Manza. 2006. „Reply to Myles: Theory and Methods for Comparative Opinion/Social Policy Research.“ American Sociological Review 71 (3): 499-502. Burstein, Paul. 2003. „The Impact of Public Opinion on Public Policy: A Review and an Agenda." Political Research Quarterly 56 (1): 29, https://doi.org/10.2307/3219881. Burstein, Paul. 2006. „Why Estimates of the Impact of Public Opinion on Public Policy are Too High: Empirical and Theoretical Implications.“ Social Forces 84 (4): 2273-2289. Burstein, Paul. 2010. „Public Opinion, Public Policy, and Democracy. “ Pp. 63-79 in Leicht K. T., J. C. Jenkins (eds.). Handbook of Politics., . Handbooks of Sociology and Social Research Springer New York https://doi.org/10.1007/978-0-387-68930-2_4.

Burstein, Paul, April Linton. 2002. „The Impact of Political Parties, Interest Groups, and Social Movement Organizations on Public Policy: Some Recent Evidence and Theoretical Concerns." Social Forces 81 (2): 380-408, https://doi.org/10.1353/sof.2003.0004. Campbell, Andrea Louise. 2012. „Policy Makes Mass Politics.“ Annual Review of Political Science 15 (1): 333-351, https://doi.org/10.1146/annurev-polisci-012610-135202.

Christian, Jennifer. 2008. „When Does Public Opinion Matter?“ The Journal of Sociology \& Social Welfare 35 (1).

Ciuk, David J., Berwood A. Yost. 2016. „The Effects of Issue Salience, Elite Influence, and Policy Content on Public Opinion." Political Communication 33 (2): 328-345, https://doi.org/10.1080/10584609.2015.1017629.

Converse, Philip E. 2006. „The nature of belief systems in mass publics (1964).“ Critical Review 18 (1-3): 1-74, https://doi.org/10.1080/08913810608443650.

Cox, J. Robert. 2010. Environmental Communication and the Public Sphere, 2nd ed. Thousand Oaks, Calif: Sage Publications.

Crespi, Irving. 2013. The Public Opinion Process: How the People Speak. Abingdon: Routledge.

Dahl, Robert. 1971. Polyarchy: Participation and Opposition. New Haven: Yale University Press.

Devine-Wright, Patrick, Susana Batel, Oystein Aas, Benjamin Sovacool, Michael Carnegie Labelle, Audun Ruud. 2017. „A conceptual framework for understanding the social acceptance of energy infrastructure: Insights from energy storage." Energy Policy 107 : 27-31, https://doi.org/10.1016/j.enpol.2017.04.020.

Disch, Lisa. 2011. „Toward a Mobilization Conception of Democratic

Representation.“ American Political Science Review 105 (01): 100-114, https://doi.org/10.1017/S0003055410000602.

Dixon, John, Kevin Durrheim, Manuela Thomae. 2017. „The Principle-Implementation Gap in Attitudes Towards Racial Equality (and How to Close It)." Political Psychology 38 : 91-126, https://doi.org/10.1111/pops.12393. 
Druckman, James N. 2013. „Public opinion: Stunted policy support.“ Nature Climate Change

3 (7): 617-617, https://doi.org/10.1038/nclimate1939.

Druckman, James N. 2014. „Pathologies of Studying Public Opinion, Political

Communication, and Democratic Responsiveness." Political Communication 31 (3):

467-492, https://doi.org/10.1080/10584609.2013.852643.

Eagly, Alice Hendrickson, Shelly Chaiken. 1993. The Psychology of Attitudes. Fort Worth, TX:

Harcourt Brace Jovanovich College Publishers.

Easton, David. 1965. A Systems Analysis of Political Life. New York: Wiley.

Erikson, Robert S. 2007. „Does Public Ignorance Matter?“ Critical Review 19 (1): 23-34, https://doi.org/10.1080/08913810701499619.

Esaiasson, Peter, Christopher Wlezien. 2017. „Advances in the Study of Democratic

Responsiveness: An Introduction." Comparative Political Studies 50 (6): 699-710, https://doi.org/10.1177/0010414016633226.

Esaiasson, Peter, Mikael Gilljam, Mikael Persson. 2017. „Responsiveness Beyond Policy

Satisfaction: Does It Matter to Citizens?" Comparative Political Studies 50 (6): 739-765, https://doi.org/10.1177/0010414015626445.

Gaunt, Martin, Tom Rye, Simon Allen. 2007. „Public Acceptability of Road User Charging:

The Case of Edinburgh and the 2005 Referendum.“ Transport Reviews 27 (1): 85-102, https://doi.org/10.1080/01441640600831299.

Gilens, Martin, Benjamin I. Page. 2014. „Testing Theories of American Politics: Elites, Interest Groups, and Average Citizens." Perspectives on Politics 12 (03): 564-581, https://doi.org/10.1017/S1537592714001595.

Hakhverdian, Armen. 2012. „The Causal Flow between Public Opinion and Policy:

Government Responsiveness, Leadership, or Counter Movement?" West European

Politics 35 (6): 1386-1406, https://doi.org/10.1080/01402382.2012.713751.

Hochschild, Jennifer. 1981. What's Fair? American Beliefs about Distributive Justice.

Cambridge: Harvard University Press.

Hoff-Elimari, Eivind, Anat Bardi, Simon Matti, Kristina Östman. 2014. „Collective action problems: Disentangling possible feedback loops between government policies and the public's value-change." European Journal of Government and Economics 3 (1): 24-46. Huang, Jason L., Paul G. Curran, Jessica Keeney, Elizabeth M. Poposki, Richard P. DeShon. 2012. „Detecting and Deterring Insufficient Effort Responding to Surveys.“ Journal of Business and Psychology 27 (1): 99-114, https://doi.org/10.1007/s10869-011-9231-8. Johnson, John A. 2005. „Ascertaining the validity of individual protocols from Webbased personality inventories.“ Journal of Research in Personality 39 (1): 103-129, https://doi.org/10.1016/j.jrp.2004.09.009.

Johnson, Martin, Paul Brace, Kevin Arceneaux. 2005. „Public Opinion and Dynamic Representation in the American States: The Case of Environmental Attitudes*." Social Science Quarterly 86 (1): 87-108, https://doi.org/10.1111/j.0038-4941.2005.00292.x. 
Kallbekken, Steffen, Håkon Sælen. 2011. „Public acceptance for environmental taxes: Selfinterest, environmental and distributional concerns." Energy Policy 39 (5): 2966-2973, https://doi.org/10.1016/j.enpol.2011.03.006.

Kraft, Michael E. 2011. Environmental Policy and Politics, 5th ed. Upper Saddle River, N.J: Pearson Prentice Hall.

Krosnick, Jon A., Bo Maclnnis. 2013. „Does the American public support legislation to reduce greenhouse gas emissions?" Daedalus 142 (1): 26-39.

Kyselá, Eva. 2018. Public responses to climate change mitigation policies. Dissertation thesis, Prague: Faculty of Arts, Charles University, 195 p. Available online: https://is.cuni.cz/webapps/zzp/detail/137771/

Manza, Jeff, Fay Lomax Cook. 2002. „A Democratic Polity? Three Views of Policy Responsiveness to Public Opinion in the United States." American Politics Research 30 (6): 630-667, https://doi.org/10.1177/153267302237231.

Manza, Jeff, Clem Brooks. 2012. „How Sociology Lost Public Opinion A Genealogy of a Missing Concept in the Study of the Political." Sociological Theory 30 (2): 89-113, https://doi.org/10.1177/0735275112448054.

Matti, Simon. 2009. Exploring public policy legitimacy: a study of belief-system correspondence in Swedish environmental policy. Luleå: Political Science Unit, Luleå University of Technology $p$.

Meade, Adam W., S. Bartholomew Craig. 2012. „Identifying careless responses in survey data." Psychological Methods 17 (3): 437-455, https://doi.org/10.1037/a0028085.

Mehrtens, F. John. 2004. „Three Worlds of Public Opinion? Values, Variation, and the Effect on Social Policy.“ International Journal of Public Opinion Research 16 (2): 115-143, https://doi.org/10.1093/ijpor/16.2.115.

Moy, Patricia. 2008. „Pluralistic Ignorance and Nonattitudes. “ Pp. 164-171 in The SAGE Handbook of Public Opinion Research. 1 Oliver's Yard, 55 City Road, London EC1Y 1SP United Kingdom: SAGE Publications Ltd.

Nisbet, Matthew C. 2011. „Public Opinion and Participation. “ Pp. 355-368 in Dryzek J. S., R. B. Norgaard, D. Schlosberg (eds.). Oxford handbook of climate change and society., . Oxford handbooks Oxford, UK ; New York: Oxford University Press.

Olmastroni, Francesco. 2010. „Public Opinion Research in Political Science.“ The IAPSS Journal of Political Science 7.

Pacheco, Julianna. 2013. „Attitudinal Policy Feedback and Public Opinion The Impact of Smoking Bans on Attitudes towards Smokers, Secondhand Smoke, and Antismoking Policies." Public Opinion Quarterly 77 (3): 714-734, https://doi.org/10.1093/poq/nft027.

Page, Benjamin I. 1994. „Democratic Responsiveness? Untangling the Links Between Public Opinion and Policy." PS: Political Science \& Politics 27 (01): 25-29, https://doi.org/10.2307/420453. 
Page, Benjamin I. 2002. „The semi-sovereign public. “ Pp. in Manza J., F. L. Cook, B. I. Page (eds.). Navigating public opinion: Polls, policy, and the future of American democracy. New York: Oxford University Press.

Page, Benjamin I., Robert Y. Shapiro. 1983. „Effects of Public Opinion on Policy." American

Political Science Review 77 (01): 175-190, https://doi.org/10.2307/1956018.

Page, Benjamin I., Robert Y. Shapiro. 2010. The Rational Public: Fifty Years of Trends in Americans' Policy Preferences. University of Chicago Press.

Pawson, Ray, Geoff Wong. 2013. „Public Opinion and Policy-making.“ Social Policy \& Administration 47 (4): 434-450, https://doi.org/10.1111/spol.12028.

Perrin, Andrew J., Katherine McFarland. 2011. „Social Theory and Public Opinion.“ Annual Review of Sociology 37 (1): 87-107, https://doi.org/10.1146/annurev.soc.012809.102659. Price, Vincent, Donald J. Roberts. 1987. „Public opinion processes. “ Pp. 781-816 in Berger,

Charles R., Steven H. Chaffee (eds.). Handbook of Communication Science. Beverly Hills: SAGE.

Price, Vincent, Peter Neijens. 1997. „Opinion Quality in Public Opinion

Research.“ International Journal of Public Opinion Research 9 (4): 336-360,

https://doi.org/10.1093/ijpor/9.4.336.

Ramonet, Ignacio. 2003. Tyranie médií. Praha: Mladá fronta.

Roberts, Jane. 2011. Environmental Policy, 2. ed. Abingdon: Routledge.

Rosa, Eugene, Aaron McCright, Ortwin Renn. 2013. „The Emergence of Systemic Risks.

“Pp. 123-129 in The Risk Society Revisited: Social Theory and Risk Governance.

Philadelphia: Temple University Press.

Rugeley, Cynthia R., John David Gerlach. 2012. „Understanding Environmental

Public Opinion by Dimension: How Heuristic Processing Mitigates High

Information Costs on Complex Issues." Politics \& Policy 40 (3): 444-470, https://doi.org/10.1111/j.1747-1346.2012.00352.x.

Sartori, Giovanni. 1993. Teória Demokracie, 1st ed. Bratislava: Archa.

Shapiro, Robert Y. 2011. „Public Opinion and American Democracy.“ Public Opinion Quarterly 75 (5): 982-1017, https://doi.org/10.1093/pog/nfr053.

Soroka, Stuart N., Christopher Wlezien. 2010a. Degrees of Democracy: Politics, Public Opinion, and Policy. Cambridge University Press.

Soroka, Stuart N., Christopher Wlezien. 2010b. „Public Opinion and Public Policy. “ Pp. in The Oxford Handbook of Canadian Politics. New York: Oxford University Press.

Soss, Joe, Sanford F. Schram. 2007. „A Public Transformed? Welfare Reform as Policy Feedback.“ American Political Science Review null (01): 111-127, https://doi.org/10.1017/S0003055407070049.

Staerklé, Christian. 2009. „Policy Attitudes, Ideological Values and Social

Representations." Social and Personality Psychology Compass 3 (6): 1096-1112, https://doi.org/10.1111/j.1751-9004.2009.00237.x. 
Stimson, James A., Michael B. MacKuen, Robert S. Erikson. 1994. „Opinion and policy: A global view.“ PS, Political Science \& Politics 27 (1): 29.

Svallfors, Stefan. 2010. „Policy feedback, generational replacement, and attitudes to state intervention: Eastern and Western Germany, 1990-2006." European Political Science Review 2 (01): 119-135, https://doi.org/10.1017/S1755773909990257.

Svallfors S. (ed.) 2007. The Political Sociology of the Welfare State: Institutions, Social Cleavages, and Orientations. Stanford University Press.

Tvinnereim, Endre, Kjersti Fløttum, Øyvind Gjerstad, Mikael Poul Johannesson, Åsta Dyrnes Nordø. 2017. „Citizens' preferences for tackling climate change. Quantitative and qualitative analyses of their freely formulated solutions." Global Environmental Change 46 : 34-41, https://doi.org/10.1016/j.gloenvcha.2017.06.005.

Tyler, Tom R. 2000. „Social Justice: Outcome and Procedure.“ International Journal of

Psychology 35 (2): 117-125, https://doi.org/10.1080/002075900399411.

Vandeweerdt, Clara, Bart Kerremans, Avery Cohn. 2016. „Climate voting in the US

Congress: the power of public concern." Environmental Politics 25 (2): 268-288, https://doi.org/10.1080/09644016.2016.1116651.

Weaver, Alicia A. 2008. „Does Protest Behavior Mediate the Effects of Public

Opinion on National Environmental Policies? A Simple Question and

a Complex Answer.“ International Journal of Sociology 38 (3): 108-125,

https://doi.org/10.2753/IJS0020-7659380305.

Wlezien, Christopher. 2004. „Patterns of Representation: Dynamics of

Public Preferences and Policy.“ The Journal of Politics 66 (1): 1-24,

https://doi.org/10.1046/j.1468-2508.2004.00139.x.

Wlezien, Christopher. 2016. „Public Opinion and Policy Representation: On

Conceptualization, Measurement, and Interpretation." Policy Studies Journal n/a-n/a, https://doi.org/10.1111/psj.12190.

Zvěřinová, Iva, Milan Ščasný, Eva Kyselá. 2014. What Influences Public Acceptance of the Current Policies to Reduce GHG Emissions? Prague: Charles University Environment Center.

A B O U T A U T H O R

Eva Kyselá is a Junior Researcher at the Department of Sociology at Charles University, where she lectures on environmental sociology and risk. Her research interests include public attitudes to environmental and climate change policies, related theoretical concepts, measurement and methodology, as well as theories of risk and risk perception. 